\title{
CONSTRUÇÃO DO SISTEMA SOCIAL DA SAÚDE A PARTIR DA TEORIA SISTÊMICA DE NIKLAS LUHMANN
}

Construction of the social healthcare system based on Niklas Luhmann's Systems Theory

\footnotetext{
${ }^{1}$ Universidade do Vale do Rio dos Sinos. São Leopoldo/RS, Brasil.

2 Scuola Dottorale Internazionale Tullio Ascarelli. Roma, Itália.
}

Correspondência: Sandra Regina Martini Vial. E-mail: srmvial@terra.com.br.

Recebido em: 16/06/2014. Revisado em: 13/11/2014. Aprovado em: 18/03/2015. 


\section{RESUMO}

A sociedade diferenciada funcionalmente é resultado do processo de evolução e especialização das comunicações internas da própria sociedade, o qual é marcado pela operação dos sistemas a partir de funções específicas. As bases teóricas para a discussão deste artigo encontram-se na Teoria dos Sistemas Sociais, desenvolvida por Niklas Luhmann, cuja postura teórica opera com um alto nível de complexidade e, exatamente por isso, apresenta vários desassossegos, uma vez que rompe com pressupostos tradicionais das ciências sociais. A abordagem proposta por Luhmann nos permite aprofundar também as possibilidades de novas construções teóricas, como o sistema da saúde, embora este não tenha sido desenvolvido especificamente pelo autor, que trata apenas do sistema médico. Por isso, um dos objetivos centrais desta reflexão é demonstrar a possibilidade da saúde como um sistema social diferenciado funcionalmente.

\section{Palavras-Chave}

Sistemas Sociais; Teoria Sistêmica; Sistema da Saúde.

\section{ABSTRACT}

A functionally differentiated society is the result of a process of evolution and specialization in communication within the society itself, marked by systems operation through specific functions. The theoretical basis for the discussion in this article is found in the Social Systems Theory developed by Niklas Luhmann, whose theoretical position operates at a high level of complexity. It is precisely for this reason that it leads to disquiet, since it breaks from traditional suppositions within the social sciences. Furthermore, the approach proposed by Luhmann allows us to dig deeper into the possibilities for new theoretical constructs, such as the application of this theory in healthcare systems, However, this is not developed specifically by the author, who considers only medical systems. Thus, one of the central objectives of this reflection is to show the possibility of perceiving healthcare as a functionally differentiated social system.

\section{Keywords}

Healthcare Systems; Social Systems; Social Systems Theory. 


\section{Introdução}

Partimos del supuesto de que los sistemas complejos pueden desarrollar y conservar un orden sistémico específico, sólo bajo la condición de que su entorno sea de una complejidad más elevada ${ }^{1}$.

Luhmann adota a complexidade da sociedade moderna e o processo evolutivo como pontos de partida de sua reflexão. Assim, temos que a sociedade, ao longo da história, foi especializando as comunicações e, com isso, identificando diferenças entre os mais diversos sistemas sociais. Luhmann, sobretudo, tratou de desconstruir velhos paradigmas das ciências sociais, em especial da sociologia, iniciando pela própria delimitação dessa disciplina e pela definição de sociedade. Para ele, a sociedade é muito mais do que um conjunto de indivíduos que agem e interagem; é também a diferença entre sistema e ambiente. Essa diferença não distancia os indivíduos da sociedade, mas os coloca no ambiente; por isso, trata-se de uma diferença constitutiva. Com esses - e muitos outros - pressupostos, Luhmann estudou vários sistemas sociais; porém, não trabalhou o sistema da saúde, e sim o sistema da medicina. Entretanto, sua indagação de como a ordem social é possível permite-nos refletir/questionar: é possível tratar a saúde como um sistema social diferenciado funcionalmente? Quais as limitações para essa construção?

Assim, a construção teórica da saúde como um sistema social, em uma sociedade em permanente transformação, é possível, embora apresente algumas limitações, as quais serão superadas por meio do paradoxo limite/possibilidade. Observamos que o sistema da saúde apresenta claramente autorreferência e autopoiese e, assim, diferencia-se do seu ambiente. Esse será o foco de nossa reflexão, a qual sabemos, ser mais pautada pelas limitações do que pelas possibilidades e, exatamente por isso, é desafiadora ou produtora de desassossegos. São esses desassossegos que tornam valores, como saúde, importantes tanto para o sistema da política como para o sistema do direito.

Esse valor, porém, tem sentido porque é indeterminado. Giancarlo Corsi², em várias discussões, compara-o com o valor happiness [felicidade] na Constituição norte-americana, pois, embora ninguém pense seriamente em ser feliz, não se põem limites no que os indivíduos podem imaginar para o próprio futuro. Pode-se, inclusive, dizer que é uma legitimação constitucional da autodeterminação, mas qualquer esforço para especificar o que significa concretamente happiness seria "anticonstitucional” exatamente porque discriminaria e limitaria a autodeterminação. O mesmo argumento é utilizado para a saúde, pois se questiona quem define o que é saúde. Assim, é oportuno recordar a complexidade e a possibilidade que o

${ }^{1}$ LUHMANN, Niklas.¿Como es posibe el orden social? Tradução Pedro Morandé Court. México: Editorial Herder, 2009. p. 23.

${ }^{2}$ Ver, por exemplo, o seguinte texto: CORSI, Giancarlo; BARALDI, Claudio; ESPOSITO, Elena. Luhmann in Glossario: i concetti fondamentali della teoria dei sistemi social. Milano: Franco Angeli, 1996. p. 222-223. 
conceito ampliado de saúde nos dá. Ao contrário do que se pode imaginar, a saúde, como sistema social, pode ser programada e decidida, e os argumentos para isso vêm da própria teoria - que, ao mesmo tempo em que mostrou que a saúde não se constitui um sistema, pode também (este é o esforço deste artigo) dar fundamentos teóricos para mostrar uma construção exatamente contrária.

Para isso, precisamos considerar que as transformações da sociedade atual são maiores do que aquelas que podemos prever e mais profundas e mais rápidas do que em qualquer outro momento histórico. Por isso, é necessário repetir e esquecer para assim entender o novo do novo, ou o velho do novo e o novo do velho. Realmente, estamos apenas no início de uma sociedade altamente complexa. Esse cenário (novo/velho) apresenta-se como desafio para novas análises, estudos e pesquisas. As teorias têm mostrado suas limitações, mas também suas possibilidades, estas que, muitas vezes, são visíveis somente através das limitações. É nesse jogo que precisamos ousar a partir de teorias que desafiam certezas, mas que, ao mesmo tempo, propõem uma análise mais fecunda para esta sociedade que está apenas no início. Nela, o presente deve ser entendido como diferença entre futuro e passado, e assim temos um problema com relação à certeza, o que acaba estimulando o desenvolvimento de uma dimensão temporal das experiências vividas e das ações. É neste tempo que tanto a certeza como a incerteza devem ser respondidas, que as expectativas sociais são continuamente frustradas/satisfeitas. É dizer: é a complexidade social em permanente incremento.

As teorias ou as ciências produzem efeitos diversos para quem estuda seriamente sua condição de analisar os fenômenos sociais. No caso específico da Teoria dos Sistemas Sociais de Niklas Luhmann ${ }^{3}$, este efeito transforma-se em desassossego porque rompe com pressupostos e verdades, e isso é sempre complexo e desafiador. Esta teoria se apresenta com vários diferenciais, pois, além de desacomodar qualquer pesquisador, também, e ao mesmo tempo, apresenta-se como um desafio para a análise da complexidade social, uma vez que não aceita as teorias tradicionais na sua íntegra, mas as utiliza para mostrar as fragilidades internas da própria teoria. Toda a base de construção da teoria é transdisciplinar e construtivista; isso, por um lado, facilita o processo de compreensão da sociedade atual, mas, por outro, não "admite" análises lineares, ou seja, cada análise pode ser diferente da que foi formulada. Esses desassossegos serão tratados no início do artigo, recordando que o próprio autor (Luhmann) referia a importância dessas inquietações. A seguir, vamos tratar da possibilidade de definir a saúde como um sistema social diferenciado funcionalmente. Muito embora o autor não tenha trabalhado diretamente com o sistema da saúde, mas com o sistema médico, vários elementos da teoria nos dão base para defender

\footnotetext{
${ }^{3}$ Esse caráter que desassossega e rompe o "tradicional" pode ser percebido em todas as obras de Niklas Luhmann. Destacamos, a título de exemplo, os seguintes textos: LUHMANN, Niklas. Sociologia do direito I. Trad. Gustavo Bayer. Rio de Janeiro: Tempo Brasileiro, 1983; LUHMANN, Niklas; DE GIORGI, Raffaele. Teoria della società. 8. ed. Milano: Franco Angeli, 1996. LUHMANN, Niklas. La sociedade de la sociedade. Trad. Javier Nafarrete. México: Herder, 2007 e LUHMANN, Niklas. El derecho de la sociedad. México: Universidad Iberoamericana, 1998.
} 
a postura de que a saúde é um sistema social e, com isso, abordaremos como conclusão aspectos da complexidade deste sistema social.

\section{Inquietações da Teoria Sistêmica ${ }^{4}$}

(...) una disciplina adquire caráter universal no en la medida en que está constituída por objetos (o clases de objetos), por extractos del mundo real, sino por la delimitación de um problema ${ }^{5}$.

Luhmann, ao descrever a necessidade de uma teoria que desse conta da análise da complexidade social, parte de várias inquietações fundamentais e "consolidadas" nas ciências sociais, como, por exemplo, a substituição da diferença entre sujeito e objeto pela diferença entre sistema e ambiente. Essa ruptura proporciona a análise da ciência a partir do problema que se deve enfrentar. Temos, então, outro foco para a análise dos problemas sociais dos quais se ocupará a sociologia: não mais a diferença entre sujeito e objeto, mas o problema que será tratado, pois a delimitação do problema é fundamental no interior da disciplina como subsistema da ciência, fazendo com que a própria disciplina, ao analisar o problema, analise a si mesma. Ao tratar do problema, Luhmann apresenta um desconforto, ao afirmar:

Los problemas fundamentales no constituyen fines para la investigación. Su irresolutiblidad se corresponde más bien con la excesiva complejidad del entorno del sistema [...] Las teorías que resuelven el problema fundamental de su disciplina, resuelven con ello un problema irresoluble 6 .

O desassossego que a Teoria provoca foi tema de muitos congressos, colóquios e artigos acusando-a, inclusive, de "anti-humanista" e conservadora. Esse desassossego foi primeiramente discutido por Luhmann, quando afirma que o projeto que ele pretende encontra dificuldades iniciais na definição do próprio projeto. Mais do que isso, ele propõe a eliminação da diferença sujeito/objeto, proposta já apresentada por outras teorias, como as marxistas - que afirmam não haver a possibilidade dessa separação, mas que não criam novas categorias para resolver a complexidade dessa situação. A Teoria Sistêmica propõe a distinção sistema/ambiente, não com a pretensão de resolver a complexidade, mas de desvelá-la. Fazer essa operação significa tentar definir o social e a própria sociedade, tarefa enfrentada por Luhmann em todos os textos e reflexões, porém uma tarefa que ele próprio diz inconclusa. $\mathrm{O}$ ponto de referência para essa discussão é sempre a ideia de que o social só pode ser pensado e discutido na própria sociedade, o único locus do social.

\footnotetext{
${ }^{4}$ Esse capítulo pretende realizar uma pequena demarcação teórica antes de introduzir propriamente o sistema social da saúde.

${ }^{5}$ LUHMANN, Niklas.¿Como es posibe el orden social?, cit., p. 18.

${ }^{6}$ Id. Ibid., p. 27.
} 
Em vários textos, Luhmann trata o problema das ciências sociais abordando os temas não de um modo linear, mas sempre buscando nas mais diversas áreas do conhecimento fundamentos para suas afirmações, como é o caso da matemática, da biologia, da física, entre outras disciplinas. Juntamente com Raffaele De Giorgi, no livro Teoria Della Società, ele aprofunda essa reflexão, trazendo das primeiras às últimas páginas "inquietações" para os novos pesquisadores das ciências sociais. Assim, escolhemos apresentar neste artigo apenas dois autores, críticos estudiosos da Teoria Sistêmica, embora saibamos que outros brasileiros, latino-americanos ou europeus poderiam contribuir para esse debate. Entretanto, escolhemos estes dois autores por entender a pertinência e prudência das reflexões que fazem. Iniciaremos apresentando as observações de Celso Campilongo, hoje um dos maiores estudiosos da Teoria Sistêmica no Brasil:

Luhmann é um desmancha-prazeres das teorias entusiastas em relação aos movimentos sociais. Sua desconfiança em relação aos sujeitos, aos atores, à ação individual ou coletiva, aos valores morais, à teologia do progresso, do desenvolvimento e da emancipação, de um lado, e sua perseverança nas explicações baseadas na diferenciação funcional, na complexidade, seletividade e contingência dos sistemas sociais e no paradoxal jogo de abertura cognitiva e fechamento operacional dos processos de comunicação - 'autopoiesis'-, fazem da teoria dos sistemas modelo ostensivamente contracorrente ${ }^{7}$.

Campilongo, nesta observação, trata dos movimentos sociais, porém a mesma observação serve para o que chamamos no Brasil de efetivação dos direitos humanos. Em vários momentos, Luhmann foi criticado por sua postura "científica", porém tais críticas, se levadas a sério, perdem o sentido, pois o autor deixa claro que a função da ciência é analisar a realidade, e não "salvar" a humanidade - até porque, se a "salvasse", ao mesmo tempo a estaria "matando".

Atualmente, a "Escola Sistêmica” está consolidada na América Latina. Alguns seguem estudando os desassossegos da teoria, como Osvaldo Dallera, na Argentina, que possivelmente nos auxilia a refletir por que a teoria continua a "molestar" tanto:

La sociologia de Luhmann molesta porque (...) interpela, desafía y pone en aprietos al pensamiento tradicional e sus variantes pre modernas y modernas. ¿Cómo hace la sociología de Luhmann para molestar y ser irritante? Básicamente hace tres cosas: (...) Desplaza del centro de la escena social a las autoridades del pensamiento tradicional;(...) Hace de la observación el motor de la construcción social de la realdad; (...) Asume que todo lo que no es social pasa a formar parte de todo lo demás que se agrupa en el campo ecológico ${ }^{8}$.

\footnotetext{
${ }^{7}$ CAMPILONGO, Celso F. Interpretação do direito e movimentos sociais. Rio de Janeiro: Elsevier, 2012. p. 42. ${ }^{8}$ DALLERA, Osvaldo. La sociedad como sistema de comunicación: la teoría sociológica de Niklas Luhmann en 30 lecciones. Buenos Aires: Biblos, 2012. p. 131.
} 
Tem razão Dallera em utilizar a expressão "molesta". Para muitos, basta ouvirem o nome do autor para se sentirem molestados, mas esta "moléstia" tem feito com que grande parte dos mesmos críticos à teoria não leia o autor - porque, além de molestar, a Teoria Sistêmica desconstrói pressupostos que sempre consideramos válidos e propõe constantemente uma nova reflexão, ou melhor, uma nova observação da própria observação. Isso desacomoda qualquer leitor que busca respostas imediatas e definitivas.

Entretanto, o maior desassossego provocado pela Teoria está na definição de novos sistemas sociais, frutos do próprio processo evolutivo, como o sistema da saúde. Por isso, iniciaremos discutindo a definição de sistema, para depois chegarmos ao sistema médico, momento em que apresentaremos a maneira como, teoricamente, pode ser definido esse "novo" sistema social: a saúde.

\section{0 sistema social da saúde}

(...) o direito à saúde pode ser resgatado e efetivado, pois não basta dizer que saúde é um direito do cidadão e um dever do Estado, é preciso criar condições para que este direito seja efetivado, e isso se dará somente através de políticas públicas que respeitem as diferenças loco-regionais, mas que apresentem uma estrutura global, pois os problemas de saúde não são territorialmente limitados?.

De modo geral, o direito afirma como direito universal qualquer valor (na perspectiva de Luhmann) que possa ser constitucionalizado. Temos, assim, o direito ao acesso à saúde, à educação, à habitação, ao lazer, mas não é possível especificar como esses direitos devem se realizar. Cabe, então, aos sistemas sociais a função de legitimá-los. Obviamente, nesse aspecto, é fundamental entender como os sistemas organizam-se internamente para isso. No caso específico do sistema da saúde, como as políticas públicas, a partir das decisões coletivamente vinculantes do sistema da política, organizam as unidades de saúde, os hospitais, os ambulatórios e também as técnicas utilizadas.

A limitação que encontramos (que também é possibilidade) é que, todas as vezes em que refletimos sobre o sistema médico, não encontramos o conceito ampliado de saúde. Encontramos apenas a saúde como mera ausência de doença, e este conceito não é compatível com a proposta que estamos desenvolvendo. Adotamos como pressuposto de nosso estudo que saúde é um bem da comunidade, concordando com a definição da Organização Mundial da Saúde (OMS), ampliando-a e adotando a ideia de que, para definir saúde, é preciso entender os determinantes

${ }^{9}$ VIAL, Sandra Regina Martini. Saúde e determinantes sociais: uma situação paradoxal. Comparazione e Diritto Civile, v. 1, p. 16, 2010. 
sociais em saúde. Não buscamos (e, mesmo que buscássemos, não encontraríamos) respostas ou certezas, mas procuramos entender essa nova situação desde a Teoria Sistêmica. Luhmann, quando estudou o sistema médico, não tinha a preocupação com a dimensão que estamos dando para o conceito de saúde e para o direito ao direito à saúde. Ele descreveu o sistema tal como se apresentava, dizendo inclusive que o sistema médico só tem sentido quando opera com o código negativo, ou seja, com a doença. Esse fator nos desassossega de modo constante e tem sido objeto de várias discussões em eventos acadêmicos.

Fato é que, cada vez que procuramos o sistema da medicina, encontramos o sistema da saúde. Essa limitação é nosso atual desassossego, tanto que há mais de dez anos temos discutido sobre a saúde como um sistema social com vários pensadores da Teoria Sistêmica, em especial com Giancarlo Corsi. Assim, o desafio que nos propomos é reduzir a complexidade, mostrando que a saúde é um sistema - embora saibamos que reduzir a complexidade é sempre, ao mesmo tempo, incrementá-la ${ }^{10}$.

No caso específico do sistema da saúde, temos de revisitar várias teorias e disciplinas para darmos conta dessa tarefa, pois, cada vez que definimos um conceito, estabelecemos distinções, indicando alguma coisa que o diferencia de outros. Por isso, assim transitamos na perspectiva construtivista: construímos e desconstruímos constantemente distinções, produto da observação de várias ordens e fruto de uma complexidade que apresenta várias dificuldades e que, muitas vezes, tem de ser definida de forma tautológica.

Se o conceito de diferenciação funcional foi tema de desconforto, hoje é um dos conceitos mais aceitos pela academia, ou seja, a ideia de que a democracia só é possível em sociedades diferenciadas funcionalmente é relativamente pacífica. Mesmo sabendo que a democracia tem em sua possibilidade também suas limitações, diferenciar diversos sistemas sociais é extremamente importante para que se possa pensar na realização de uma democracia, pois somente em uma sociedade diferenciada funcionalmente podemos efetivar a soberania popular, inclusive questionando-a. Deste modo, é possível entender como a democracia encobre muitas vezes o poder ou, em alguns casos, é encoberta por ele, o que também proporciona a diferença entre os sistemas da política, do direito, da educação e todos os sistemas sociais diferenciados.

A sociedade, como um sistema social, é composta por subsistemas e é constituída por comunicações, ou seja, é uma malha de comunicações. Sem comunicação,

\footnotetext{
10 “A complexidade não é uma operação que um sistema efetua ou que nele se verifica: complexidade é um conceito da observação e da descrição. Devemos nos perguntar, então: qual é a forma deste conceito, qual é a distinção o que o constitui? já esta pergunta leva a uma infinidade de reflexões que se conectam, porque o conceito de complexidade não é um conceito simples, mas é um conceito por vezes complexo e, por sua vez, formado de um modo autológico". (Tradução da autora). LUHMANN, Niklas; DE GIORGI, Raffaele. op. cit., p. 40.
} 
não é possível fazer nenhuma seleção/escolha. A necessidade de seleção (escolha) decorre justamente do fato de que o sistema não consegue dar conta desse contingente de possibilidades, isto é, da complexidade interna. Esse excesso de possibilidades é proporcional à gama de elementos do seu interior, e as relações entre esses elementos fazem crescer o número de possibilidades. Esse crescente número de possibilidades torna a sociedade altamente complexa, de risco e em permanente evolução. É exatamente esse processo evolutivo que permite a constante diferenciação funcional: as possibilidades não realizadas ficam potencializadas como opções para o futuro e, de algum modo, são absorvidas pelo sistema. O sistema seleciona algumas possibilidades, opções que estejam em consonância com a função que ele desempenha. É a simplificação da complexidade do ambiente a condição de sobrevivência do sistema, mas isso desencadeia o aumento da complexidade do sistema. O número de possibilidades aumenta internamente, podendo até gerar sua autodiferenciação, resultando em novos subsistemas ${ }^{11}$. O motivo que enseja sua evolução é a sobrevivência à complexidade, que cria constantemente novas possibilidades. Ou seja, na tentativa de reduzir a complexidade, dá-se o incremento dela.

Diante disso, também podemos afirmar que a saúde se constitui em um sistema social diferenciado funcionalmente. A dificuldade de alguns com esse entendimento está vinculada - pelo menos em alguns casos - ao fato de que Luhmann nunca escreveu nada sobre o sistema da saúde, mas sobre o sistema médico. Acreditamos que a teoria ofereça elementos suficientes para afirmarmos que, no processo evolutivo, a saúde foi aprimorando suas comunicações e estruturando-se como um subsistema social, ou como um sistema social.

Seguindo a própria definição de sistema social, vemos que a saúde enquadra-se perfeitamente bem no conceito de sistema social, pois surge por "autocatálise" dos problemas de dupla contingência. Ademais, um sistema social precisa diferenciar-se de seu ambiente e ter uma estrutura própria, ser fechado operativamente e aberto cognitivamente. Aliás, somente esse fato pode justificar a ideia de irritação entre sistema do direito e sistema da saúde, ambos sistemas fechados, mas em constante irritação, especialmente em países da periferia da modernidade onde o direito é constantemente "chamado" a decidir sobre questões "não decididas" por outros subsistemas. O que faz o sistema do direito é processualizar as informações que vêm de outros sistemas por meio de sua linguagem interna, de seu código e de sua estrutura, ou seja, quando algum sistema irrita outro, temos um processo normal e necessário para a própria evolução. $\mathrm{O}$ que não pode acontecer é que os sistemas irritados decidam com códigos diferentes dos seus. Em outros termos: os

${ }^{11}$ Para elucidar tal situação, tome-se como exemplo o caso do direito: inicialmente o sistema do direito diferenciou-se em público e privado. Entretanto, dada a sua crescente complexidade, viu-se obrigado a se autodiferenciar em constitucional, administrativo, penal, comercial, e assim sucessivamente. Esse processo revela a evolução do sistema, que é diferente do desenvolvimento, passível de controle; a evolução não é controlável. Ver LUHMANN, Niklas. Sociologia do direito I, cit. 
sistemas sociais que não decidem com seus códigos estão provocando uma corrupção, o que não é adequado, pois, quando um sistema decide com o código do outro, perdemos a possibilidade da diferenciação funcional. Os reflexos dessa eventual "corrupção" são percebidos, por exemplo, através do déficit democrático que temos atualmente. Se para Luhmann o sistema médico tem uma estrutura própria, vemos que através dessa observação é possível pensar no sistema da saúde. Porém, não podemos desconsiderar as observações do autor sobre o sistema médico, ou melhor, sobre medicina, pois ele afirma que o "sistema da medicina" é igual ao sistema da "cura dos doentes" - o que atualmente pode ser questionado, pois não está claro na Teoria Sistêmica qual o conceito de saúde utilizado. Hoje, é senso comum entender a saúde para muito além da cura dei malati: ora, se assim entendemos, obviamente outra compreensão é possível ter desse sistema.

Interessante observar que Luhmann escreveu poucos artigos sobre o sistema médico, nos quais a saúde aparece sempre como parte do código binário saúde/doença - ou melhor, do código são/doente. Alerta Luhmann, no entanto, que os conceitos de são e de doente não indicam um particular estado físico ou psíquico, porquanto o que ativa o sistema da saúde não é a saúde. O que terá importância será a doença. Pode parecer absurdo, porém é fundamental destacar o que o autor quer dizer com isso: para os médicos, a questão a ser resolvida é a doença, não a saúde.

[...] non dà niente da fare, consente solo di riflettere su ciò che viene a mancare quando si è malati. Il sistema della medicina opera, dunque, soltanto quando qualcuno si ammala. Corrispondentemente, vi sono molte malattie e una sola salute: la terminologia della malattia si sviluppa, mentre Il concetto di salute rimane problematico o vuoto $^{12}$.

Ora, se o sistema da medicina opera somente quando alguém adoece, estamos distantes do conceito de direito à saúde, constitucionalizado em grande parte dos países. Ou ainda podemos concluir que o autor já se referia às dificuldades de efetivar e dimensionar a própria definição da OMS sobre saúde, bem como as especificidades da saúde em cada comunidade. Outro aspecto relevante é que o valor significativo para o sistema da medicina não é o valor positivo (estar são), mas sim a doença, já que, no sistema da medicina, esses programas só operam orientados para a doença, em que a atuação do médico se dá pelo valor atribuído à própria doença. Aqui temos mais uma razão para pensar no sistema da saúde, no qual o médico não atua como única figura. Em outros termos:

\footnotetext{
12 “(...) não dá para fazer nada, vamos apenas pensar sobre o que é perdido quando o indivíduo está doente. 0 sistema médico opera, então, só quando alguém fica doente. Do mesmo modo, há muitas doenças e uma só saúde: a terminologia da doença se desenvolve, enquanto o conceito de saúde continua a ser problemático ou vazio". (Tradução da autora). CORSI, Giancarlo; BARALDI, Claudio; ESPOSITO, Elena. op. cit. p. 143.
} 
I programmi della medicina si producono soltanto nel contesto della codificazione sano/malato e, quindi, sono orientati alla malattia [...] Poiché Il suo valore positivo è la malattia, la medicina non ha neppure costruito una teoria della reflessione. L'agire medico deriva dal valore attribuito alla salute: ma la salute non crea collegamenti nel sistema e, dunque, non c' è nulla su cui riflettere ${ }^{13}$.

Outro aspecto é que o valor relevante para o sistema da medicina é não estar são, ou seja, o sistema é ativado com a doença, já que para Luhmann o sistema da medicina opera orientado pela doença.

Com essas observações, podemos ver que Luhmann deixa indicativos para se pensar na saúde como um sistema social, em cujo contexto ele destaca a existência do código binário referido, mas alerta para a constatação de que o valor que "vale" é o negativo, ou seja, a doença: ela é que faz o sistema "funcionar" e ser funcionalmente diferenciado dos demais sistemas sociais, mas sempre conectado nessa rede de comunicação que é a própria sociedade, como podemos observar:

Le interdipendenze tra medicina ed altri sistemi di funzioni sono molto importanti. Il sistema della medicina è strutturalmente accoppiato con l' economia, la scienza, Il sistema giuridico e cosi via: la cura medica richiede decisioni politiche, conoscenze scientifiche, finanziamenti, regolazione giuridica. La interdipendenze non intaccano l' autonomia del sistema della medicina: possono essere coinvolti uffici del lavoro, sedute parlamentari, commissioni etiche, preti, parenti, ma la costruzione della malattia rimane matéria della medicina ${ }^{14}$.

Aqui temos mais indicativos da possibilidade, independentemente de Luhmann ter escrito sobre a saúde constituir-se em sistema social. Além disso, ele aponta para o caráter transdisciplinar e interssetorial da saúde, mesmo afirmando que doença é a matéria da medicina. Para os sanitaristas, essa abordagem pode render críticas, porém essa não é nossa preocupação: queremos mostrar que o autor deixa instrumentos suficientes para o entendimento da saúde como um sistema

\footnotetext{
13“Os programas da medicina se produzem apenas no contexto da codificação saudável/doente e, por conseguinte, são orientados para a doença (...) porque o seu valor positivo é a doença, a medicina não tem sequer construído uma teoria da reflexão. 0 ato médico deriva do valor atribuído para a saúde: mas a saúde não cria ligações no sistema e, portanto, não há nada para refletir". (Tradução da autora). CORSI, Giancarlo; BARALDI, Claudio; ESPOSITO, Elena. op. cit. p. 144.

14 "As interdependências entre medicina e outros sistemas de funções são muito importantes. 0 sistema médico é estruturalmente acoplado à economia, à ciência, ao sistema legal e assim por diante: a assistência médica requer decisões políticas, conhecimentos científicos, financiamento, regulamentação legal. As interdependências não afetam a autonomia do sistema da medicina: podem estar envolvidos escritórios de trabalho, sessões parlamentares, comissões de ética, padres, familiares, mas a construção da doença continua a ser uma matéria da medicina". (Tradução da autora). CORSI, Giancarlo; BARALDI, Claudio; ESPOSITO, Elena. op. cit. p. 145.
} 
diferenciado funcionalmente. Temos outra passagem interessante que nos leva para esse caminho, aquela na qual Luhmann afirma que o sistema médico pode ter também um código secundário:

Si, afferma, invece, la possibilità di un códice secondario, grazie alla tecnologia genética: la distinzione geneticamente perfetto/geneticamente preoccupante permette di determinare una distinzione secondaria curabile/incurabile, riferita alla malattia: la cura dei malati viene poi richiesta su entrambi i lati della distinzione ${ }^{15}$.

Ou seja, Luhmann percebeu a complexidade que envolve o sistema da medicina e deixou espaços para novas reflexões que ultrapassam os campos médico, ético e político. Com isso, mostra que, evolutivamente, o campo da medicina vem ampliando-se, motivado pela inflação das possibilidades de tratamento, bem como pelos seus custos.

Sabe-se que a imutabilidade não é característica dos sistemas, visto que o ambiente é efetivamente complexo, e isso os influencia internamente. Com a saúde, não foi diferente, especialmente se pensarmos na diferenciação funcional do direito até chegarmos ao direito à saúde. Deve-se dizer que a diferenciação do sistema não significa decomposição de um todo em partes, e sim que cada subsistema tem seu próprio entorno. Não existe um agente externo que modifica: é o próprio sistema que, por uma questão de sua sobrevivência no ambiente, realiza essa diferenciação. Justamente em face dessa mutabilidade, ele foi capaz de se autoproduzir e, assim, alcançamos a expectativa jurídica da saúde. Ele foi irritado suficientemente para fazer sua seleção e, dentro dela, a seleção da saúde com o intuito de torná-la expectativa jurídica (regra) ${ }^{16}$.

Importante referir que o sistema da educação ${ }^{17}$, amplamente estudado por Luhmann, também opera a partir do código negativo. Porém, em ambos os sistemas sociais, temos a unidade de uma diferença. Em termos de educação, podemos falar em uma distinção entre um ato educativo e uma intencionalidade de educar. $\mathrm{Na}$ saúde, um ato curativo e a intencionalidade da cura. Todos os sistemas sociais operam com códigos: no caso específico em estudo, temos dois sistemas que operam com o código negativo, ou seja, o que irrita o sistema da saúde é a doença, e o que irrita a

\footnotetext{
15 “Afirma-se, no entanto, a possibilidade de um código secundário, graças à tecnologia genética: a distinção do geneticamente perfeito/geneticamente preocupante nos conduz a determinar uma distinção secundária curável/incurável, referida à doença: o tratamento e a cura dos pacientes são, então, necessários em ambos os lados da distinção" (Tradução da autora). CORSI, Giancarlo; BARALDI, Claudio; ESPOSITO, Elena. op. cit. p. 146.

${ }^{16}$ Nesse sentido, VIAL, Sandra Regina Martini. O Sistema da Saúde e o Sistema da Educação: uma reflexão sobre as expectativas e a constante necessidade de reforma. In STRECK, Lenio Luiz; ROCHA, Leonel Severo; ENGELMANN, Wilson (Orgs.). Constituição, sistemas sociais e hermenêutica: anuário do Programa de Pós-Graduação em Direito da Unisinos. Porto Alegre: Livraria do Advogado, 2011. p. 233-234.

${ }^{17}$ Id. Ibid., p. 221-241.
} 
educação é o não aprendizado. Esse código reflete constantemente a complexidade na relação professor-aluno ou operador da saúde-doente. Referindo-se ao sistema da educação, Corsi faz a seguinte observação:

Siamo in presenza dunque di unarticulazione di distinzioni che operano sempre simultaneamente: da un lato la differenza tra comportamenti giusti e comportamenti sbagliati, che si traduce nella differenza tra lo stato attuale dellallievo e lo stato futuro che il docente proietta e che desidera raggiungere mediante lintervento educativo; dall'altro lato la differenza tra l'intenzione pedagogica del docente e la reazione ad essa da parte dellallievo ${ }^{18}$.

Essa postura de perceber o mundo, a sociedade, é que permitiu entender a educação a partir da heterogeneidade do sistema, como intencionalidade de educar, autopoiese que permite $\mathrm{o}$ acoplamento com outros sistemas sociais, mostrando, com isso, as limitações ou a desmistificação de que a educação pode levar à "perfeição" do ser humano. Além desses aspectos, mostra também que o sistema educativo opera sempre com um código positivo/negativo, o que "desacomoda" vários pedagogos (resposta esperada, pois a teoria efetivamente veio para desassossegar!).

\section{Conclusões}

As irritações sofridas pelo direito na década de 1980 para constitucionalizar o direito à saúde é o que hoje possibilita acoplamentos, pois é a partir dos dispositivos constitucionais (em especial aquele que diz que a "saúde é direito de todos e dever do Estado") que permeiam o sistema do direito que o sistema da política poderá agir - algumas vezes, como é o caso, por meio de políticas públicas de saúde.

Os fatores que influenciaram essa relação entre esses sistemas são a positivação do direito e a democratização da política. Essa relação é estreita, mas os sistemas são livres de coincidências e fechados no seu operar. Assim, é possível dizer que a democratização da política precisa de mais proteção jurídica ao particular, especialmente no que tange ao âmbito do direito constitucional.

A comunicação entre os sistemas do direito e da política foi/é muito importante, pois o sistema do direito, por si só, não consegue dar conta da efetividade da saúde, tampouco da pretensão de torná-la direito, lá nos anos 1980. Diante de um quadro de complexidade do ambiente, contingência e evolução social, foi possível

\footnotetext{
18 “Estamos, portanto, na presença de uma articulação de distinções que sempre operam simultaneamente: por um lado, a diferença entre os comportamentos certos e comportamentos errados que se traduzem na diferença entre o estado atual e o estado futuro do aluno que o professor projeta e que deseja alcançar por meio da intervenção educacional; por outro lado, a diferença entre a intenção pedagógica do professor e a reação a ele por parte do estudante". (Tradução da autora). CORSI, Giancarlo. Sistemiche apprendono. Lecce: Pensa Multimidia, 1998. p. 64-65.
} 
acoplar isso ao direito, ou seja, os anseios político-sociais daquele momento irritaram o direito para que a saúde fosse direito de fato (expectativa normativa).

Todavia, quando acontece o acoplamento estrutural entre dois sistemas, há uma espécie de coordenação estável das operações respectivas ${ }^{19}$, pois, caso ocorresse tal fusão, haveria a corrupção dos sistemas, gerando o caos.

Reações e manifestações provocam transformações no sistema social - é preciso olhar o passado para produzir novas alternativas. Ou seja, quem decide leva em consideração o passado, a opinião pública, os movimentos de protesto, mas por fim a decisão não é tomada por nenhum desses elementos: é tomada dentro da estrutura em que está inserida. Da mesma forma, por ser tomada dentro dessa estrutura, será também objeto de oposição, muitas vezes dos próprios grupos que contribuíram para aquela tomada de decisão, justamente porque, ao decidir, toma-se partido de uma ou outra parte.

O problema está quando a decisão não é tomada dentro das estruturas, ou seja, pelas instituições que a compõem, tornando seus efeitos ainda mais imprevisíveis. As estruturas não conduzem mudanças ou a não mudança ${ }^{20}$, mas estas devem se dar através das estruturas.

Os processos de mudança social chamados endógenos-exógenos são observados no longo prazo: desenvolvendo-se, eles produzem resultados que podem afetar não somente as regras de funcionamento do sistema em que aparecem, mas também o entorno do sistema, provocando uma reação deste último.

Enfim, sistema da saúde ou da medicina? Para Luhmann, interessou somente esclarecer o que é a função da medicina e, por isso, tratou somente deste sistema. A medicina cura as doenças e as constrói também, mas não produz saúde porque esta não existe! É necessário considerar sempre que os códigos binários (doença/saúde, direito/não direito etc.) não indicam necessariamente a situação da realidade. Indicam comunicação ${ }^{21}$ : quando um juiz dá razão para uma parte e não para a outra, não afirma que a outra parte poderia não ter razão; diz somente que deve decidir e,

\footnotetext{
${ }^{19} \mathrm{CORSI}$, Giancarlo; BARALDI, Claudio; ESPOSITO, Elena. op. cit., p. 20.

20 "I mutamenti di struttura nel sistema e i mutamenti nell'ambiente hanno luogo senza coordinamento; se dovessero essere coordinati, ci si dovrebbe preoccupare ad hoc per le casualità che ne deriverebbero". "As mudanças de estrutura no sistema e as mudanças no ambiente têm seu lugar sem que haja uma coordenação; se devessem ser coordenados, deveriam se preocupar ad hoc pela casualidade que dela derivariam". (Tradução da autora). LUHMANN, Niklas; DE GIORGI, Raffaele. op. cit., p. 273.

${ }^{21}$ Se pode dizer também que os códigos marcam a comunicação e não a realidade. Se quisermos entender porque um lado e não outro (por exemplo: por que um médico não prescreveu uma terapia, marcando a situação como saudável), então é necessário observar o observador e não a realidade (isto é o médico e não o corpo). Do mesmo modo, no direito: para entender porque um juiz dá razão a uma parte e não a outra é preciso observar o juiz (por exemplo, através das motivações da sentença) e não a causa. Por isso se fala de observação de segunda ordem como modalidade moderna, sem exceção. Como consequência: todas as decisões são discutíveis, pelo menos em princípio. Desse modo, o sistema se mantém dinâmico, sem confundir-se com a realidade que descreve, e isso é o pressuposto da possibilidade de evoluir.
} 
assim, demarca no sentido positivo ou negativo a própria decisão. Do mesmo modo, quando um profissional da saúde diz que alguém não tem uma doença, não afirma que tal pessoa é completamente sã; diz somente que não encontra motivos para intervir e, assim, marca sua decisão, ou o contrário, naturalmente. Nesse sentido, o valor do código que tem cognitividade é aquele da doença, independentemente do fato que prefere o paciente, que é ter saúde.

A sociedade, como um sistema social, é composta por subsistemas e constituída por uma malha de comunicações. O fato é que essa ampla malha de comunicações aumenta o número de possibilidades, o que torna a sociedade altamente complexa. Mas não só isso: as possibilidades não realizadas são absorvidas pelo sistema e tornam-se potenciais opções para o futuro; ficam na memória do sistema. Nessa linha, o sistema seleciona os elementos conforme a função de cada sistema diante da necessidade de evolução e sobrevivência à complexidade, o que cria novas possibilidades: buscando a redução da complexidade, dá-se o incremento dela própria. Por isso, afirmar que a saúde se constitui em um sistema social diferenciado funcionalmente não foge à razão: a teoria nos oferece pressupostos capazes de, diante do processo evolutivo, sustentar que a saúde aprimorou suas comunicações e estruturou-se como um subsistema social, ou em sistema social, diante das complexidades advindas da própria sociedade.

\section{Referências}

CAMPILONGO, Celso F. Interpretação do direito e movimentos sociais. Rio de Janeiro: Elsevier, 2012.

CORSI, Giancarlo. Sistemiche apprendono. Lecce: Pensa Multimidia, 1998.

; BARALDI, Claudio; ESPOSITO, Elena. Luhmann in Glossario: i concetti fondamentali della teoria dei sistemi social. Milano: Franco Angeli, 1996.

DALLERA, Osvaldo. La sociedad como sistema de comunicación: la teoría sociológica de Niklas Luhmann en 30 lecciones. Buenos Aires: Biblos, 2012.

LUHMANN, Niklas.¿Como es posibe el orden social? Tradução Pedro Morandé Court. México: Editorial Herder, 2009.

El derecho de la sociedad. México: Universidad Iberoamericana, 1998. . Organizzazione e decisione. Milano: Brundo Mondadori, 2005.

. La sociedade de la sociedade. Trad. Javier Nafarrete. México: Herder, 2007.

. Sociologia do direito I. Trad. Gustavo Bayer. Rio de Janeiro: Tempo Brasileiro, 1983.

; DE GIORGI, Raffaele. Teoria della società. 8. ed. Milano: Franco Angeli, 1996. 
VIAL, Sandra Regina Martini. Saúde e determinantes sociais: uma situação paradoxal. Comparazione e Diritto Civile, v. 1, p. 1-24, 2010.

O Sistema da Saúde e o Sistema da Educação: uma reflexão sobre as expectativas e a constante necessidade de reforma. In STRECK, Lenio Luiz; ROCHA, Leonel Severo; ENGELMANN, Wilson (Orgs.). Constituição, sistemas sociais e hermenêutica: anuário do Programa de Pós-Graduação em Direito da Unisinos. Porto Alegre: Livraria do Advogado, 2011.

Sandra Regina Martini Vial - Doutora em Direito, Evoluzione dei Sistemi Giuridici e Nuovi Diritti pela Università Degli Studi di Lecce; pós-doutora em Direito pela Università degli studi di Roma Tre. Professora da Universidade do Vale do Rio dos Sinos e da Scuola Dottorale Internazionale Tullio Ascarelli; professora visitante da Università Degli Studi di Salerno. São Leopoldo/RS, Brasil.E-mail: srmvial@terra.com.br. 